\title{
Correlation Of The Interaction Of Agricultural Production With The Volume Of Dehkanproduction In Uzbekistan
}

\author{
Bunyod Utanov, Tashkent Institute of Finance, Tashkent Institute of Finance Republic of Uzbekistan \\ Baxtiyor Mamatkulov, Tashkent Institute of Finance, Tashkent State University of Economics Republic of \\ Uzbekistan \\ Mavluda Akhmedova, Tashkent State University of Economics, Tashkent State University of Economics \\ Republic of Uzbekistan \\ Jahongir Murodov, Tashkent State University of Economics, Tashkent State University of Economics \\ Republic of Uzbekistan \\ Dilnoza Abdiqulova, Tashkent Institute of Finance, Tashkent State University of Economics Republic of \\ Uzbekistan
}

\begin{abstract}
This article examines the problems of agriculture and agricultural production in Uzbekistan, the analysis and statistics of the World Bank.

The purpose of the scientific article is to analyze the dynamics of changes in agriculture in Uzbekistan in 2000-2019, to analyze the impact of agricultural production on agricultural production by economic and mathematical methods.

As a result of the research, the following conclusions were drawn:

Through the development of agriculture in the country, it is possible to increase the export potential of Uzbekistan, while preventing food risks;

An economic interpretation of the model parameters is possible - an increase in $\mathrm{X}$ by 1 unit of measure leads to an increase in $Y$ by an average of 1.008 units. The obtained estimates of the regression equation allow us to use it for forecasting. With $\mathrm{x}=11$, Y will be in the range from 10.28 to 10.52 units and with a 95\% probability it will not go beyond these limits
\end{abstract}

Keywords: agriculture, export, agricultural products, agricultural land, agricultural production, fruit and vegetable products, cotton fiber.

$\begin{array}{lll}\text { Received: 03.12.2020 } & \text { Accepted: 18.01.2021 } & \text { Published: 02.02.2021 }\end{array}$

\section{Introduction}

Agriculture, which accounts for 32\% of Uzbekistan's GDP and employs $27 \%$ of the working population, can be one of the key factors in the country's economic growth in the context of effective public policy.

According to 2019 data, cotton fiber exports accounted for $1.6 \%$ of total exports, and at a time when this figure is declining from year to year, it is important to consider the development of other areas of agriculture in the country.

To do this, it is necessary to remove obstacles to the transformation of agriculture into a competitive sector, as well as one that serves the interests of the private sector, the population and the state. World Bank analysis shows that there are currently five major challenges to achieving this goal. Including:

- It is necessary to balance the use of agricultural land;

- It is necessary to increase the productivity of agricultural products;

- It is necessary to make maximum use of export opportunities for agricultural development;

- It is necessary to increase the efficiency of the use of budget funds to finance agriculture;

- It is necessary to protect the land ownership rights of farms [1];

- Special attention should be paid to increasing the export potential of the industry and increasing the production of value-added products. For example, in Turkey, \$2,000 per hectare is grown, in Egypt \$ 8,000 , and in Israel \$12,000. In Uzbekistan, the figure does not exceed \$ 300. Our products are not able to compete in foreign markets due to the fact that the supply of goods of the same standard is not always established.

In the course of this study, we will study in detail the directions of agricultural development in the country. 
Agriculture, one of the most important factors in ensuring food security for the world's population, has been studied by experts in this field as well as by leading economists.

In a study conducted by Shi-wei Xu, Yu Wang, Sheng-wei Wang, Jian-zheng LI [2], based on the theory of abnormal oscillations of information about agricultural products and studies that have a significant impact on society methods for determining the vibration limits of agricultural product data at different time scales are discussed in detail. Based on data and survey data from the National Bureau of Statistics (NBS) of China, various statistical methods were used in this article to determine the limits of agricultural production, consumption, and price advance warning. Together with Delphi's method of mutual acquaintance, it has finally repeatedly identified the limits of early warning of information about agricultural products and conducted an early warning analysis of changes in agricultural monitoring data in 2018. The results show that: daily, weekly and monthly monitoring and early warning limits for agricultural products play an important warning role in monitoring abnormal changes in agricultural production; the limits of long-term monitoring and early warning of agricultural product data set by the research institute can provide effective early warning of current abnormal changes in agricultural products, in China can provide a reference standard for the production, consumption and price monitoring of dairy products. the early macro level at the national macro level and further improve the monitoring and early warning application of Chinese agricultural products.

Research by Rozélia Laurett, Arminda Paco, and Emerson Wagner Mainardes [3] focuses on Brazilian family farmers 'understanding of sustainable development in agriculture, its past, barriers, and implications. For this purpose, a survey was conducted with the participation of 23 farmers and qualitative research was conducted. An interview scenario was developed with subsequent content analysis to collect data. The results showed that farmers adopt sustainable development in agriculture according to 25 definitions. The study identified 19 pioneers in ensuring sustainability in agriculture; 20 barriers to sustainable development in agriculture; and 14 results of sustainable agriculture. This study provides an in-depth understanding of how sustainable development in agriculture depends on its predecessors, as well as its barriers and impacts on agriculture. The results confirm that understanding and understanding what sustainable development is is a process, and that the concept may vary in different contexts. This study aims to study Brazilian family farming in terms of sustainability.

Among the scientists of our country N. Khushmatov [4], A.Khojabekov [5], J.Ataev [6].

In the scientific research of J. Ataev the efficiency of the organization of activities of farms and dehkan farms, the factors influencing their success are conditionally divided into six groups. Given that the organization of any business entity, the effectiveness of which depends directly on the mental, physical, socio-economic thinking potential of the entrepreneur, the characteristics of the leader, as well as the characteristics of the economy are considered as factors affecting its activities. These factors contribute to the development of small business, ensuring an increase in operational efficiency in terms of quantity and quality. Informational, environmental, technical and technological, social factors and other services are also mentioned as factors that directly affect economic activity [6].

\section{Research methodology}

Along with the method of analysis and synthesis, economic-mathematical methods were used in the study to express the relationship between agricultural production and farm products.

\section{Analysis and results}

In the Republic of Uzbekistan, agriculture is important as a sector with high potential and wide opportunities. All factors affecting agriculture are divided into groups: social, economic, and directly related to both, the development of science and technology, land resources and composition, and environmental factors. In our country, which has favorable economic, social and land resources, the volume of agricultural production is growing from year to year.

In 2000 , the share of farms in total agricultural output was $66.7 \%$, and the share of farms was $5.5 \%$, while in 2019 these figures were $68.3 \%$ and $27.9 \%$, respectively. -jadval). Among the agricultural and livestock products produced in the Republic of Uzbekistan, milk, honey and vegetables have the highest share, followed by cereals and legumes, eggs and others. 
The structure of agricultural production, in percent [7]

\begin{tabular}{|l|l|l|l|l|}
\hline & \multirow{2}{*}{$\begin{array}{l}\text { All categories of } \\
\text { farms }\end{array}$} & Farms & $\begin{array}{l}\text { Dehkan (personal } \\
\text { assistant) farms }\end{array}$ & $\begin{array}{l}\text { Organizations } \\
\text { engaged } \\
\text { agricultural } \\
\text { activities }\end{array}$ \\
\hline 2000 & 100 & 5,5 & 66,7 & 27,8 \\
\hline 2005 & 100 & 24,3 & 61,7 & 14 \\
\hline 2010 & 100 & 36,3 & 61,6 & 2,1 \\
\hline 2015 & 100 & 30,7 & 66,9 & 2,4 \\
\hline 2016 & 100 & 29,7 & 68,0 & 2,3 \\
\hline 2017 & 100 & 29,3 & 68,4 & 2,3 \\
\hline 2018 & 100 & 26,0 & 71,2 & 2,8 \\
\hline 2019 & 100 & 27,9 & 68,3 & 3,8 \\
\hline
\end{tabular}

According to the World Bank, the reduction of cotton and wheat fields in Uzbekistan, for example, by reducing them to $50 \%$, will lead to an increase in gross agricultural output by $51 \%$, agricultural employment by $16 \%$ and water saving by $11 \%$.

How quickly should these lands be converted to more profitable crops? This process should be gradual and coordinated with changes in neighboring sectors. For example, the redistribution of land for growing fruits and vegetables should take place simultaneously with the improvement of agrologistics within the state and its customs borders. This, in turn, ensures rapid delivery of perishable fruits and vegetables from farmers to local consumers and the international market.

Otherwise, the profit from the processing of fruits and vegetables will be less than the profit from the sale of wheat and cotton.

The average yield of cotton, wheat, tomatoes, potatoes, milk and other products in Uzbekistan is much lower than their real potential. Increasing this figure will not only increase the profits and exports of farms and agro-organizations, but also create an opportunity to use the areas currently occupied with wheat and cotton for more profitable crops.

Issues such as insufficient funding for research and services over the decades and insufficient provision of services needed to develop the sector need to be addressed. In 2018, only $0.02 \%$ of Uzbekistan's gross agricultural output will be spent on agricultural research. However, at present, information and consulting services for local farmers are not available at all.

For comparison, middle-income countries with successful agriculture spend 1 percent of their gross agricultural output on agricultural research, while high-income countries spend an average of 2.5 percent.

The correlation model of the impact of growth in farm production in the country on the total volume of agricultural production was analyzed.

Based on the correlation field, it can be hypothesized (for the general population) that the relationship between all possible values of $\mathrm{X}$ and $\mathrm{Y}$ is linear.

The linear regression equation is $\mathrm{y}=\mathrm{bx}+\mathrm{a}$

The estimated regression equation (constructed from the sample data) will have the form $\mathrm{y}=\mathrm{bx}$ $+a+\varepsilon$, where ei are the observed values (estimates) of the errors $\varepsilon i$, $a$ and $b$, respectively, the estimates of the parameters $\alpha$ and $\beta$ of the regression model to be found.

To estimate the parameters $\alpha$ and $\beta$ - use least squares method (least squares method).

System of normal equations.

$$
\begin{aligned}
& \mathrm{a} \cdot \mathrm{n}+\mathrm{b} \cdot \sum \mathrm{x}=\sum \mathrm{y} \\
& \mathrm{a} \cdot \sum \mathrm{x}+\mathrm{b} \cdot \sum \mathrm{x} 2=\sum \mathrm{y} \cdot \mathrm{x}
\end{aligned}
$$

Table 2

To calculate the regression parameters, let's build a calculation table 


\begin{tabular}{|c|c|c|c|c|}
\hline $\mathrm{x}$ & $\mathrm{y}$ & $x^{2}$ & $\mathrm{y}^{2}$ & $x^{*} y$ \\
\hline 7.235 & 6.5465 & 52.3458 & 42.8566 & 47.3642 \\
\hline 7.652 & 6.9903 & 58.5527 & 48.8637 & 53.4893 \\
\hline 8.088 & 7.4078 & 65.4164 & 54.8755 & 59.9146 \\
\hline 8.3147 & 7.6506 & 69.1336 & 58.5324 & 63.6125 \\
\hline 8.4372 & 7.7965 & 71.187 & 60.7856 & 65.781 \\
\hline 8.6959 & 8.1087 & 75.6185 & 65.7503 & 70.512 \\
\hline 8.9278 & 8.3464 & 79.7059 & 69.6625 & 74.5152 \\
\hline 9.1383 & 8.5506 & 83.5085 & 73.1136 & 78.1383 \\
\hline 9.3335 & 8.7641 & 87.1143 & 76.8089 & 81.7995 \\
\hline 9.5199 & 8.9983 & 90.629 & 80.9687 & 85.6628 \\
\hline 10.3371 & 9.8047 & 106.8558 & 96.1325 & 101.3524 \\
\hline 10.7208 & 10.161 & 114.9345 & 103.2463 & 108.9337 \\
\hline 10.9286 & 10.3285 & 119.435 & 106.678 & 112.8764 \\
\hline 11.104 & 10.4978 & 123.2985 & 110.2048 & 116.5679 \\
\hline 11.312 & 10.6735 & 127.9605 & 113.9228 & 120.7378 \\
\hline 11.509 & 10.9229 & 132.4562 & 119.3089 & 125.7108 \\
\hline 11.6579 & 11.0309 & 135.9063 & 121.6815 & 128.5973 \\
\hline 11.9063 & 11.3302 & 141.7603 & 128.3744 & 134.9014 \\
\hline 12.1411 & 11.4969 & 147.4072 & 132.1778 & 139.585 \\
\hline 12.2843 & 11.6254 & 150.9051 & 135.15 & 142.8105 \\
\hline 199.2435 & 187.0316 & 2034.1312 & 1799.0947 & 1912.8627 \\
\hline
\end{tabular}

For our data, the system of equations has the form

$20 \mathrm{a}+199.243 \cdot \mathrm{b}=187.032$

$199.243 \cdot a+2034.131 \cdot b=1912.863$

We get the empirical regression coefficients: $b=1.0079, a=-0.6892$

Regression equation (empirical regression equation):

$\mathrm{y}=1.0079 \mathrm{x}-0.6892$

1. Parameters of the regression equation. 
Selected averages.

$$
\begin{array}{r}
\bar{x}=\frac{\sum x_{i}}{n}=\frac{199.243}{20}=9.962 \\
\bar{y}=\frac{\sum y_{i}}{n}=\frac{187.032}{20}=9.352 \\
\overline{x y}=\frac{\sum x_{i} y_{i}}{n}=\frac{1912.86}{20}=95.643
\end{array}
$$

Sample variances:

$$
\begin{aligned}
& S^{2}(x)=\frac{\sum x_{i}^{2}}{n}-\bar{x}^{2}=\frac{2034.13}{20}-9.962^{2}=2.46 \\
& S^{2}(y)=\frac{\sum y_{i}^{2}}{n}-\bar{y}^{2}=\frac{1799.09}{20}-9.352^{2}=2.5
\end{aligned}
$$

Standard deviation

$$
\begin{aligned}
& S(x)=\sqrt{S^{2}(x)}=\sqrt{2.46}=1.569 \\
& S(y)=\sqrt{S^{2}(y)}=\sqrt{2.5}=1.582
\end{aligned}
$$

The correlation coefficient $\mathrm{b}$ can be found by the formula without solving the system directly:

$$
b=\frac{\overline{x \cdot y}-\bar{x} \cdot \bar{y}}{S^{2}(x)}=\frac{95.643-9.962 \cdot 9.352}{2.46}=1.0079
$$

$a=\bar{y}-b \cdot \bar{x}=9.352-1.0079 \cdot 9.962=-0.6892$

1.1. Correlation coefficient.

$$
\text { Covariance. }
$$

$\operatorname{cov}(x, y)=\overline{x \cdot y}-x \cdot \bar{y}=95.643-9.962 \cdot 9.352=2.48$

We calculate the indicator of the tightness of communication. This indicator is a selective linear correlation coefficient, which is calculated by the formula: The linear correlation coefficient takes values from -1 to +1 .

The connections between signs can be weak and strong (close). Their criteria are assessed on the Chaddock scale:

$$
\begin{aligned}
& 0.1<\text { rxy }<0.3 \text { : weak; } \\
& 0.3<\text { rxy }<0.5 \text { : moderate; } \\
& 0.5<\text { rxy }<0.7 \text { : noticeable; } \\
& 0.7<\text { rxy }<0.9 \text { : high; } \\
& 0.9<\text { rxy }<1 \text { : very high; } \\
& \text { In our example, the relationship between trait } Y \text { and factor } X \text { is very high and direct. }
\end{aligned}
$$

In addition, the linear pairwise correlation coefficient can be determined through the regression coefficient b:

$$
r_{x, y}=b \cdot \frac{S(x)}{S(y)}=1.008 \frac{1.569}{1.582}=1
$$

2.1. The significance of the correlation coefficient.

We put forward hypotheses:

H0: $\mathrm{rxy}=0$, there is no linear relationship between the variables;

$\mathrm{H} 1$ : $r x y \neq 0$, there is a linear relationship between the variables;

In order to test the null hypothesis of the equality of the general correlation coefficient of a normal two-dimensional random variable to zero at a significance level $\alpha$ with a competing hypothesis $\mathrm{H} 1$ $\neq 0$, it is necessary to calculate the observed value of the criterion (the value of the random error)

$$
t_{n a b l}=r_{x y} \frac{\sqrt{n-2}}{\sqrt{1-r_{x y}^{2}}}
$$

and from the table of critical points of the Student's distribution, for a given level of significance $\alpha$ and the number of degrees of freedom $\mathrm{k}=\mathrm{n}-2$, find the critical point tcrit of the bilateral critical region. If tobl $<$ tcrit of reasons to reject the null hypothesis. If $\left|t_{o b l}\right|>t_{\text {crit }}-$ the null hypothesis is rejected. 


$$
t_{n a b l}=1 \frac{\sqrt{18}}{\sqrt{1-1^{2}}}=148.349
$$

According to the Student's table with a significance level $\alpha=0.05$ and degrees of freedom $k=18$, we find tcrit:

$t_{\text {crit }}(\mathrm{n}-\mathrm{m}-1 ; \alpha / 2)=\operatorname{tcrit}(18 ; 0.025)=2.445$

where $m=1$ is the number of explanatory variables.

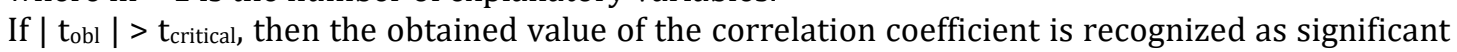
(the null hypothesis stating that the correlation coefficient is equal to zero is rejected).

Since $\left|t_{\text {obl }}\right|>t_{\text {crit, }}$ then we reject the hypothesis that the correlation coefficient is equal to 0 . In other words, the correlation coefficient is statistically significant

In paired linear regression $\mathrm{t} 2 \mathrm{r}=\mathrm{t} 2 \mathrm{~b}$, and then testing hypotheses about the significance of the regression and correlation coefficients is equivalent to testing the hypothesis about the significance of a linear regression equation.

2.2. Interval estimate for the correlation coefficient (confidence interval).

$$
\left(r-t_{\text {krit }} \sqrt{\frac{1-r^{2}}{n-2}} ; r+t_{\text {krit }} \sqrt{\frac{1-r^{2}}{n-2}}\right)
$$

$$
\begin{aligned}
& \text { Confidence } \\
& \left(1-2.445 \sqrt{\frac{1-1^{2}}{20-2}} ; 1+2.445 \sqrt{\frac{1-1^{2}}{20-2}}\right) \\
& r \in(0.983 ; 1)
\end{aligned}
$$

The linear regression equation is $y=1.008 x-0.689$

The coefficients of the linear regression equation can be given economic meaning.

The regression coefficient $b=1.008$ shows the average change in the effective indicator (in units of $y$ ) with an increase or decrease in the value of the factor $x$ per unit of its measurement. In this example, with an increase of 1 unit, $y$ increases by an average of 1.008 .

The coefficient $\mathrm{a}=-0.689$ formally shows the predicted level of $\mathrm{y}$, but only if $\mathrm{x}=0$ is close to the sampled values.

But if $x=0$ is far from the sampled values of $x$, then literal interpretation can lead to incorrect results, and even if the regression line describes the values of the observed sample quite accurately, there is no guarantee that it will also be when extrapolated to the left or right.

Substituting the corresponding $\mathrm{x}$ values in the regression equation, you can determine the aligned (predicted) values of the effective indicator $y(x)$ for each observation.

The relationship between $\mathrm{y}$ and $\mathrm{x}$ determines the sign of the regression coefficient $\mathrm{b}$ (if $>0$ - direct relationship, otherwise - reverse). In our example, the connection is direct.

Elasticitycoefficient.

The coefficient of elasticity is found by the formula:

$$
E=\frac{\partial y_{x}}{\partial x^{y}}=b \frac{\bar{x}}{\bar{y}}
$$

$$
E=1.008 \frac{9.962}{9.352}=1.074
$$

In our example, the coefficient of elasticity is greater than 1 . Therefore, when $\mathrm{X}$ changes by $1 \%, \mathrm{Y}$ will change by more than $1 \%$. In other words - $\mathrm{X}$ significantly affects $\mathrm{Y}$.

$$
\begin{aligned}
& \text { Beta coefficient } \\
& \beta_{j}=b j \frac{S(x)}{S(y)}=1.008 \frac{1.569}{1.582}=1
\end{aligned}
$$

Those. an increase in $\mathrm{x}$ by the standard deviation Sx will increase the mean $\mathrm{Y}$ value by $100 \%$ of the standard deviation Sy.

$$
\text { Approximation error. }
$$

$$
\bar{A}=\frac{\sum\left|y_{i}-y_{x}\right| y_{i}}{n} 100 \%
$$

$$
\bar{A}=\frac{0.088}{20} 100 \%=0.44 \%
$$

On average, the calculated values deviate from the actual ones by $0.44 \%$. Since the error is less than $7 \%$, this equation can be used as a regression. 
Empirical correlation relation.

$\eta=\sqrt{\frac{50.013}{50.05}}=1$

$\eta=\sqrt{\frac{\sum\left(\bar{y}-y_{x}\right)^{2}}{\sum\left(y_{i}-\bar{y}\right)^{2}}}$

Where

$$
\sum\left(\bar{y}-y_{x}\right)^{2}=50.05-0.0409=50.013
$$

Correlation index.

For linear regression, the correlation index is equal to the correlation coefficient $\mathrm{r}_{\mathrm{xy}}=1$.

The resulting value indicates that the factor $x$ significantly affects $y$

For any form of dependence, the tightness of the relationship is determined using the multiple correlation

$$
R=\sqrt{1-\frac{\sum\left(y_{i}-y_{x}\right)^{2}}{\sum\left(y_{i}-\bar{y}\right)^{2}}}
$$

coefficient:

This coefficient is universal, as it reflects the closeness of the relationship and the accuracy of the model, and can also be used for any form of relationship between variables. When constructing a one-factor correlation model, the multiple correlation coefficient is equal to the pair correlation coefficient rxy.

Unlike the linear correlation coefficient, it characterizes the tightness of the nonlinear relationship and does not characterize its direction. Changes in the range $[0 ; 1]$.

The theoretical correlation for the linear relationship is equal to the correlation coefficient rxy.

The coefficient of determination.

$\mathrm{R}^{2}=12=0.9992$

Those in $99.92 \%$ of cases, changes in $\mathrm{x}$ lead to a change in $\mathrm{y}$. In other words, the accuracy of fitting the regression equation is high. The remaining $0.08 \%$ change in $Y$ is explained by factors not taken into account in the model (as well as specification errors).

Table 3

To assess the quality of the regression parameters, let's build a calculation table

\begin{tabular}{|l|l|l|l|l|l|l|}
\hline$x$ & $y$ & $y(x)$ & $\left(y_{i-}-y_{c p}\right)^{2}$ & $(y-y(x))^{2}$ & $\left(x_{i}-x_{c p}\right)^{2}$ & $\left|y-y_{x}\right|: y$ \\
\hline 7.235 & 6.546 & 6.603 & 7.868 & 0.00319 & 7.437 & 0.00862 \\
\hline 7.652 & 6.99 & 7.023 & 5.576 & 0.00108 & 5.337 & 0.00471 \\
\hline 8.088 & 7.408 & 7.463 & 3.778 & 0.00301 & 3.512 & 0.00741 \\
\hline 8.315 & 7.651 & 7.691 & 2.893 & 0.00163 & 2.714 & 0.00528 \\
\hline 8.437 & 7.797 & 7.815 & 2.418 & 0.000328 & 2.325 & 0.00232 \\
\hline 8.696 & 8.109 & 8.075 & 1.545 & 0.00111 & 1.603 & 0.00411 \\
\hline 8.928 & 8.346 & 8.309 & 1.01 & 0.00139 & 1.07 & 0.00447 \\
\hline 9.138 & 8.551 & 8.521 & 0.641 & 0.000867 & 0.679 & 0.00344 \\
\hline 9.334 & 8.764 & 8.718 & 0.345 & 0.00213 & 0.395 & 0.00526 \\
\hline
\end{tabular}




\begin{tabular}{|l|l|l|l|l|l|l|}
\hline 9.52 & 8.998 & 8.906 & 0.125 & 0.00854 & 0.196 & 0.0103 \\
\hline 10.337 & 9.805 & 9.729 & 0.205 & 0.00566 & 0.141 & 0.00767 \\
\hline 10.721 & 10.161 & 10.116 & 0.655 & 0.00201 & 0.575 & 0.00442 \\
\hline 10.929 & 10.329 & 10.326 & 0.954 & $8.0 \mathrm{E}-6$ & 0.934 & 0.000275 \\
\hline 11.104 & 10.498 & 10.502 & 1.314 & $2.1 \mathrm{E}-5$ & 1.304 & 0.000433 \\
\hline 11.312 & 10.673 & 10.712 & 1.747 & 0.00149 & 1.822 & 0.00361 \\
\hline 11.509 & 10.923 & 10.911 & 2.469 & 0.000151 & 2.393 & 0.00113 \\
\hline 11.658 & 11.031 & 11.061 & 2.82 & 0.000884 & 2.875 & 0.0027 \\
\hline 11.906 & 11.33 & 11.311 & 3.915 & 0.000368 & 3.78 & 0.00169 \\
\hline 12.141 & 11.497 & 11.548 & 4.602 & 0.00259 & 4.748 & 0.00442 \\
\hline 12.284 & 11.625 & 11.692 & 5.17 & 0.00444 & 5.392 & 0.00573 \\
\hline 199.243 & 187.032 & 187.032 & 50.054 & 0.0409 & 49.233 & 0.088 \\
\hline
\end{tabular}

Analysis of the accuracy of determining estimates of the regression coefficients.

An unbiased estimate of the variance of disturbances is the value:

$$
\begin{array}{r}
S^{2}=\frac{\sum\left(y_{i}-y_{x}\right)^{2}}{n-m-1} \\
S^{2}=\frac{0.0409}{18}=0.00227
\end{array}
$$

$S^{2}=0.00227$ - is the unexplained variance or variance of the regression error (a measure of the spread of the dependent variable around the regression line).

$$
S=\sqrt{S^{2}}=\sqrt{0.00227}=0.0477
$$

$\mathrm{S}=0.0477$ is the standard error of the estimate.

Regression standard error is considered as a measure of the dispersion of observational data from the modeled values. The lower the value of the standard error of the regression, the higher the quality of the model.

Sa is the standard deviation of the random variable a.

$S_{a}=S \cdot \frac{\sqrt{\sum x^{2}}}{n S(x)}$

$\mathrm{S}_{\mathrm{b}}$ is the standard deviation of the random variable $\mathrm{b}$.

$S_{b}=\frac{S}{\sqrt{n} \cdot S(x)}$

$S_{b}=\frac{0.0477}{\sqrt{20} \cdot 1.569}=0.00679$

Confidence intervals for the dependent variable.

Economic forecasting based on the constructed model assumes that pre-existing relationships of variables are retained for the lead period. To predict the dependent variable of the effective indicator, it is necessary to know the predicted values of all factors included in the model. 
The predicted values of the factors are substituted into the model and point predictive estimates of the studied indicator are obtained.

$(\mathrm{a}+\mathrm{bxp} \pm \varepsilon)$

Let us calculate the boundaries of the interval in which $95 \%$ of the possible values of Y will be concentrated with an unlimited number of observations and $\mathrm{Xp}=11$

$\mathrm{t}_{\text {crit }}(\mathrm{n}-\mathrm{m}-1 ; \alpha / 2)=\mathrm{t}_{\text {crit }}(18 ; 0.025)=2.445$

$\mathrm{y}(11)=1.008 * 11-0.689=10.398$

Calculate the forecast error for the equation $y=b x+a$

$\epsilon=t_{\text {krit }} S \sqrt{\frac{1}{n}+\frac{\left(\bar{x}-x_{p}\right)^{2}}{\sum\left(x_{i}-\bar{x}\right)^{2}}}$

$\epsilon=2.445 \cdot 0.0477 \sqrt{\frac{1}{20}+\frac{(9.962-11)^{2}}{49.23}}=0.0312$

$\epsilon=t_{\text {krit }} S \sqrt{\frac{1}{n}+\frac{\left(\bar{x}-x_{p}\right)^{2}}{n\left(\overline{x^{2}}-\bar{x}^{2}\right)}}$

$\epsilon=2.445 \cdot 0.0477 \sqrt{\frac{1}{20}+\frac{(9.962-11)^{2}}{20\left(101.707-9.962^{2}\right)}}=0.0312$

10.398

$\pm$

0.0312

$(10.37 ; 10.43)$

With a probability of $95 \%$, it can be guaranteed that the value of $Y$ for an unlimited number of observations will not go beyond the found intervals.

Let us calculate the forecast error for the equation $y=b x+a+\varepsilon$

$\epsilon=t_{\text {krit }} S \sqrt{1+\frac{1}{n}+\frac{\left(\bar{x}-x_{p}\right)^{2}}{\sum\left(x_{i}-\bar{x}\right)^{2}}}$

$\epsilon=2.445 \cdot 0.0477 \sqrt{1+\frac{1}{20}+\frac{(9.962-11)^{2}}{49.23}}=0.12$

10.398

$(10.28 ; 10.52)$

Individual confidence intervals for $\mathrm{Y}$ at a given $\mathrm{X}$ value.

(a

$\mathrm{bx}_{\mathrm{i}} \pm$

Where

$\epsilon=t_{\text {krit }} S \sqrt{1+\frac{1}{n}+\frac{\left(\bar{x}-x_{i}\right)^{2}}{\sum\left(x_{i}-\bar{x}\right)^{2}}}$
$\epsilon=2.445 \cdot 0.0477 \sqrt{1+\frac{1}{20}+\frac{\left(9.962-x_{i}\right)^{2}}{49.23}}$

$\mathrm{t}_{\text {krit }}(\mathrm{n}-\mathrm{m}-1 ; \alpha / 2)=(18 ; 0.025)=2.445$

\begin{tabular}{|l|l|l|l|l|}
\hline$x_{i}$ & $y=-0.69+1.01 x_{i}$ & $\varepsilon_{i}$ & $y \min =y-\varepsilon_{i}$ & $y \max =y+\varepsilon_{i}$ \\
\hline 7.235042606 & 6.603 & 0.128 & 6.475 & 6.731 \\
\hline 7.65197573 & 7.023 & 0.125 & 6.898 & 7.149 \\
\hline 8.088039716 & 7.463 & 0.123 & 7.339 & 7.586 \\
\hline 8.314660764 & 7.691 & 0.123 & 7.569 & 7.814 \\
\hline
\end{tabular}




\begin{tabular}{|l|l|l|l|l|}
\hline 8.43724048 & 7.815 & 0.122 & 7.693 & 7.937 \\
\hline 8.695891526 & 8.075 & 0.121 & 7.954 & 8.197 \\
\hline 8.927818297 & 8.309 & 0.121 & 8.188 & 8.43 \\
\hline 9.138296422 & 8.521 & 0.12 & 8.401 & 8.641 \\
\hline 9.333504459 & 8.718 & 0.12 & 8.598 & 8.838 \\
\hline 9.519925805 & 8.906 & 0.12 & 8.786 & 9.026 \\
\hline 10.33710919 & 9.729 & 0.12 & 9.61 & 9.849 \\
\hline 10.720751 & 10.116 & 0.12 & 9.996 & 10.236 \\
\hline 10.92863269 & 10.326 & 0.121 & 10.205 & 10.446 \\
\hline 11.10398382 & 10.502 & 0.121 & 10.381 & 10.623 \\
\hline 11.31196284 & 10.712 & 0.122 & 10.59 & 10.834 \\
\hline 11.50896363 & 10.911 & 0.122 & 10.788 & 11.033 \\
\hline 11.65788431 & 11.061 & 0.123 & 10.938 & 11.183 \\
\hline 11.90631327 & 11.311 & 0.124 & 11.187 & 11.435 \\
\hline 12.14113725 & 11.548 & 0.125 & 11.423 & 11.673 \\
\hline 12.28434348 & 11.692 & 0.126 & 11.567 & 11.818 \\
\hline
\end{tabular}

With a probability of $95 \%$, it can be guaranteed that the value of $\mathrm{Y}$ for an unlimited number of observations will not go beyond the found intervals.

Testing hypotheses about the coefficients of the linear regression equation.

1) t-statistics. Student's criterion.

$\mathrm{t}_{\text {crit }}(\mathrm{n}-\mathrm{m}-1 ; \alpha / 2)=\mathrm{t}_{\text {crit }}(18 ; 0.025)=2.445$

$t_{b}=\frac{b}{S_{b}}$

$t_{b}=\frac{1.008}{0.00679}=148.35$

Since $148.35>2.445$, the statistical significance of the regression coefficient $b$ is confirmed (we reject the hypothesis that this coefficient is zero).

$$
\begin{gathered}
t_{a}=\frac{a}{S_{a}} \\
t_{a}=\frac{-0.689}{0.0685}=10.06
\end{gathered}
$$

Since 10.06>2.445, the statistical significance of the regression coefficient a is confirmed (we reject the hypothesis that this coefficient is zero).

Confidence interval for the coefficients of the regression equation.

Let us determine the confidence intervals of the regression coefficients, which with a reliability of 95\% will be as follows:

$\left(\mathrm{b}-\mathrm{t}_{\mathrm{crit}} \mathrm{Sb} ; \mathrm{b}+\mathrm{t}_{\mathrm{crit}} \mathrm{Sb}\right)$

$(1.01-2.445 * 0.00679 ; 1.01+2.445 * 0.00679)$

$(0.991 ; 1.024)$ 
With a probability of $95 \%$, it can be argued that the value of this parameter will lie within the found interval.

(a - tcrit $\left.\mathrm{Sa} ; \mathrm{a}+\mathrm{t}_{\text {crit }} \mathrm{Sa}\right)$

$(-0.689-2.445 * 0.0685 ;-0.689+2.445 * 0.0685)$

$(-0.857 ;-0.522)$

found interval.

With a probability of $95 \%$, it can be argued that the value of this parameter will lie within the

2) F-statistics. Fisher's criterion.

$$
\begin{aligned}
& R^{2}=1-\frac{\sum\left(y_{i}-y_{x}\right)^{2}}{\sum\left(y_{i}-\bar{y}\right)^{2}}=1-\frac{0.0409}{50.05}=0.9992 \\
& F=\frac{R^{2}}{1-R^{2}} \frac{n-m-1}{m} \\
& F=\frac{0.9992}{1-0.9992} \frac{20-1-1}{1}=22007.278
\end{aligned}
$$

or

Where

$$
\sum\left(y_{x}-\bar{y}\right)^{2}=50.05-0.0409=50.0128
$$

Table value of the criterion with degrees of freedom $\mathrm{k} 1=1$ and $\mathrm{k} 2=18, \mathrm{Ftabl}=4.41$

Since the actual value F> Ftabl, the coefficient of determination is statistically significant (the found estimate of the regression equation is statistically reliable).

Regression equation quality indicators.

\begin{tabular}{|l|l|}
\hline Index & Value \\
\hline Determination coefficient & 0.9992 \\
\hline Average coefficient of elasticity & 1.074 \\
\hline Average error of approximation & 0.44 \\
\hline
\end{tabular}

\section{Conclusions and recommendation}

The dependence of Y on X was studied. At the specification stage, a pairwise linear regression was chosen. Its parameters are estimated by the least squares method. The statistical significance of the equation was tested using the coefficient of determination and Fisher's test. It was found that in the studied situation $99.92 \%$ of the total variability in $\mathrm{Y}$ is explained by the change in X. It was also found that the parameters of the model are statistically significant. An economic interpretation of the model parameters is possible an increase in $\mathrm{X}$ by 1 unit of measure leads to an increase in $\mathrm{Y}$ by an average of 1.008 units. The obtained estimates of the regression equation allow us to use it for forecasting. With $x=11$, Y will be in the range from 10.28 to 10.52 units. and with a $95 \%$ probability it will not go beyond these limits.

An increase in the volume of farm production in the country by 1 unit will increase the volume of agricultural production by 1,008 units. The increase in agricultural production will create opportunities for GDP and exports.

\section{References}

1. Ways to make agriculture in Uzbekistan more efficient and competitive. https://www.gazeta.uz/uz/2019/07/08/agriculture/

2. Agricultural statistics, B. Mamatkulov, B. Utanov, textbook, 2021, "IQTISODIYOT"/Tashkent, 236 p.

3. Shi-wei XU, Yu WANG, Sheng-wei WANG, Jian-zheng LI. Research and application of real-time monitoring and early warning thresholds for multi-temporal agricultural products information, Journal of Integrative Agriculture, Volume 19, Issue 10, 2020, Pages 2582-2596, ISSN 2095-3119, https://doi.org

/10.1016/S2095-3119(20)63368 (http://www.sciencedirect.com/science/article/pii/S2095311920633688)

4. Rozélia Laurett, Arminda Pacho, Emerson Wagner Mainardes. Sustainable Development in Agriculture and its Antecedents, Barriers and Consequences - An Exploratory Study, Sustainable Production and Consumption, Volume 27, 2021, Pages 298-311, ISSN 2352-5509, 
https://doi.org/10.1016/j.spc.

2020.10 .032$.

(http://www.sciencedirect.com/science/article/pii/S2352550920313725)

5. Xushmatov N. Methodological aspects of calculating economic and economic efficiency in the fight against cotton candy. SCIENTIFIC-PRACTICAL AGRICULTURAL JOURNAL. Special issue, 2019. Pages 7-9.

6. Xo'jabekov A. Establishment of livestock clusters and the role of farms in it. SCIENTIFIC-PRACTICAL AGRICULTURAL JOURNAL. Special issue, 2019. Pages 10-13.

7. J.Ataev. Classification of the main factors influencing the development of small business in the market of agricultural products. Scientific electronic journal "Economy and Innovative Technologies". № 2, March-April, 2020. http://iqtisodiyot.tsue.uz/sites/default/files/maqolalar/17_Atayev.pdf

8. Data of the Statistics Committee of the Republic of Uzbekistan. www.stat.uz 